\title{
Researches on mechanical properties of soil under conditions of excavation unloading in Guangzhou
}

\author{
DING Jiang-shu 1, a, TIAN Bing ${ }^{2, b}$, HUANG Min 2,c , HUANG Hua ${ }^{2, \mathrm{~d}}$ \\ ${ }^{1}$ Construction Engineering Quality Testing Station of Foshan, Foshan 528000, China \\ ${ }^{2}$ School of Civil Engineering, Chang'an University, Xi'an 710061, China \\ adingjs2016@163.com, b395162484@qq.com, c1443552509@qq.com, \\ dhuanghua23247@163.com
}

\begin{abstract}
Keywords: road engineering; triaxial compression test; lateral unloading test; axial compression performance; Stress-strain curve; pore water pressure

Abstract. Based on the investigation of the distribution of strata in the downtown area of Guangzhou City, simulating the stress path of excavating foundation, the triaxial pressure tests on isotropic consolidation and $K_{0}$ consolidation conditions, the lateral unloading tests and the axial unloading tests on mucky soil and silty clay were performed by using SLB-1 stress-strain controlled triaxial shear penetration apparatus, in order to research the loading and unloading deformation properties of foundation soil, and change rules with strain and strength properties of pore water pressure under different stress paths. The results show that there exist different characters of stress-strain curves of the soil under different stress paths, mucky soil and silty clay are different in mechanical properties, while the stress-strain curves of them present obvious nonlinear type; the failure model of soil under normal triaxial compression conditions, $K_{0}$ compression conditions and lateral unloading conditions presents compression-shear type, and under the axial unloading conditions presents longitudinal stretch type; change rules of stress-strain curves of the soil are influenced by average consolidation stress, plastic index and confining pressures; change rules of pore water pressure are also influenced by average consolidation stress, stress path and properties of the soil, which can be fit by exponential decay function; stress-strain curves of pore water under $K_{0}$ compression- axial unloading conditions can be fit by quadratic parabolic equation.
\end{abstract}

\section{Introduction}

With the development of economy, the urban construction is speeding increasingly, the size and the number of underground space development is growing, the area of excavating foundation is larger and larger, the safety of underground engineering construction is increasingly getting more attention. The urban environment demands of foundation deformation control during excavation become more and more strict than before. The soil during excavating foundation is in complex stress state, and mechanical responses of soils under complicated stress during excavating foundation have become a hot and difficult spot of geotechnical engineering.

Lamn [1] presented the concept of stress path method in 1967. He [2] carried out $K_{0}$ consolidation undrained tests of silty clay in the Wu Han area to study mechanical properties of soils and obtained the stress-strain law of soil and the depression of elastic parameters of Duncan model. According to the deep reshaping clay test under the condition of long time high-pressure $K_{0}$ consolidation and "constant the axial compression, unloading the confining pressure", Chen [3] found that the longer consolidation, the greater the consolidation stress, the higher the triaxial compressive strength of soil sample. Besides, scholars respectively carried out shear test and lateral unloading test of different kinds of soil under the $K_{0}$ consolidation and conventional triaxial shear tests. By comparison, it is found that different consolidation condition and stress path have a significant impact on soil strength and stress-strain properties [4-14]. Zhao [15-16] found that stress path had a certain influence on the deformation of soil after he carried out undrained condition of unloading and loading test on the true triaxial apparatus, which proved that the generalized shear stress of soil has a nonlinear relationship with the generalized shear strain. According to the analysis about the present situation of excavating 
foundation unloading of soil test, Ma [17] introduced the conventional triaxial unloading, $K_{0}$ unloading consolidation and the true triaxial test results, briefly discussed the problems existing in various tests and future research direction. The above several experimental researches have common deficiencies, for example, research scope is narrow, the mechanical properties of unloaded soils under different stress path are not studied at the same time, the conclusion isn't generalized. Besides, the existing study of simulation experiment on soil behaviors under excavating loading of foundation pits mainly concentrates on stress-strain law under the unloading stress path. But as we all know, soil is a kind of two-phase media, whose main difference with geotechnical materials such as reinforced concrete is that the mechanical responses also include the development regularity of pore water pressure. However, the research on law of pore water pressure under different stress path is less. Moreover, the engineering properties of soil have close relationship with terrain.

Geological conditions in Guang Zhou are complex and the distribution of shallow layers in the central area is shown by Table. 1. Mucky soil and silty clay are typical layers which influence the use of shallow underground space in the center of Guang Zhou city. They are used as the research objects in this paper to simulate the triaxial test under the stress path of excavating foundation and to explore unloading deformation performance, the development law of pore pressure and the strength parameters.

Table1. Engineering geological feature of shallow soil in Guangzhou central district

\begin{tabular}{c|l}
\hline \multicolumn{1}{c|}{ Soil type } & \multicolumn{1}{c}{ Description of lithological characteristics } \\
\hline Silt-silt soil layer & $\begin{array}{l}\text { grey, dark grey, saturated flow plasticity, 0 to 3.2 meters thick, generally 3 to 5 meters } \\
\text { thick. }\end{array}$ \\
\hline Clay-silty clay layer & $\begin{array}{l}\text { Brown, yellow grey maroon with incanus, often showing irregular piebald structure, } \\
\text { normally it is plastic, locally being mixed up with sand layer and silt soil lenticle. The } \\
\text { clay soil is uniform and fine, and has a certain swelling-shrinkage and stable layer, it is } \\
\text { widely distributed, generally 3 to 5 meters thick. }\end{array}$ \\
\hline Silty clay-clay layer & $\begin{array}{l}\text { yellowish-brown, greyish, blue-grey, maroon with yellow grey, often showing irregular } \\
\text { piebald structure, showing plastic and hard-plastic, locally being hard or soft-plastic, } \\
\text { generally having a certain swelling-shrinkage, locally being mixed up with sand, silt } \\
\text { and silt soil lenticle, instability, 0 to 8.4 meters thick. }\end{array}$ \\
\hline Silt-silty clay layer & $\begin{array}{l}\text { maroon, claybank, yellowish white, black grey ect. consisting of cohesive soil, silty-fine } \\
\text { sand, breccia, gravel. all of breccia and gravel show angular shape and are in different } \\
\text { sizes. Their main component are fine quartz sandstone, siltstone, mud, and small } \\
\text { amount of lime-shale ect, soil is not uniform. the scope of thickness changes widely, } \\
\text { from 0 to 14.1 meters. }\end{array}$ \\
\hline Bedrock & $\begin{array}{l}\text { Including middle and upper carboniferous View day group of limestone, lower } \\
\text { carboniferous, measuring water coal system and stone unter den limestone. }\end{array}$ \\
\hline
\end{tabular}

\section{Introduction of the Experiment}

The stress-strain relationship analysis of soil can be regarded as a special part during excavating foundation. The soil characteristics shown by general geotechnical loading test are different from those under actual excavating foundation. There are some problems such as foundation pitting uplift, lateral soil lateral displacement during excavation. So we need explore the stress path of soil under p-q stress space by analyzing the loaded way of soil during excavation. According to analysis results, the influenced area of excavating foundation was divided into several parts shown by Fig. 1. 


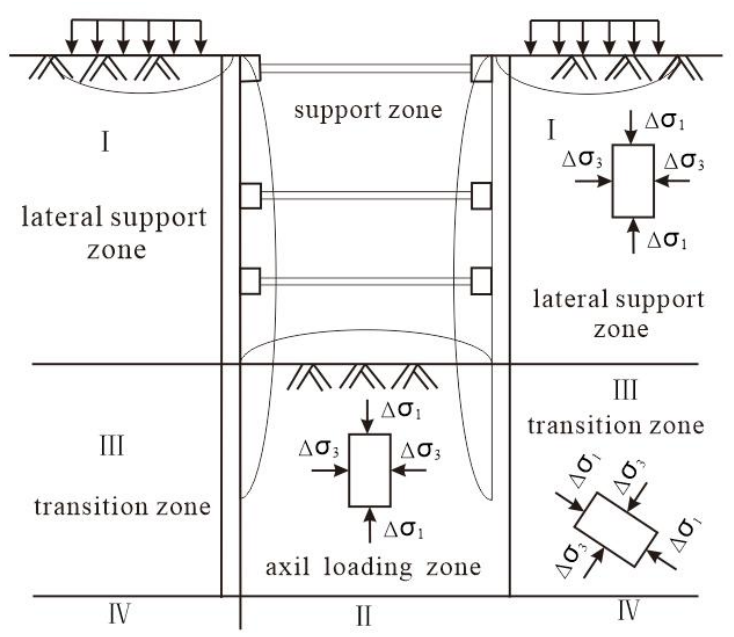

Fig. 1 Soil stress state change within the influencing scope of foundation pit

Lateral unloading zone $(\mathrm{I})$ ): stress path is shown by AC in Fig. 2.

Axial unloading zone( ${ }^{I I}$ ): Vertical stress decreases after excavation; the principal stress axis rotates, the stress path of soil is shown by AS in the Fig. 2, the strength of soil decreases and the plastic zone appears in corner.

The transitional zone $\left({ }^{\mathrm{III}}\right)$ : Vertical stress remains constant; horizontal stress gets minor change; due to the shear slid of soil, the principal stress axes' rotation will occur; the stress path is shown by AC in Fig. 2.

IV zone : Vertical stress remains constant; horizontal stress gets minor change.

The lateral and axial unloading area is the main impact area to the deformation of foundation, and the main body of lateral deformation is lateral unloading area. Experiment research will mainly revolve around these few areas, to study the mechanical properties of soil in the process of excavating foundation when soil state changes.

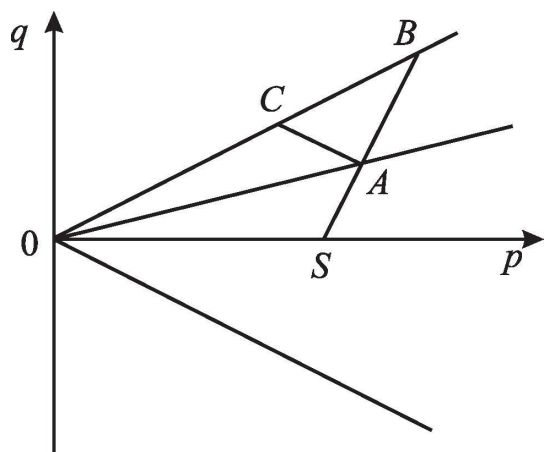

Fig. 2 p-q Stress space and path

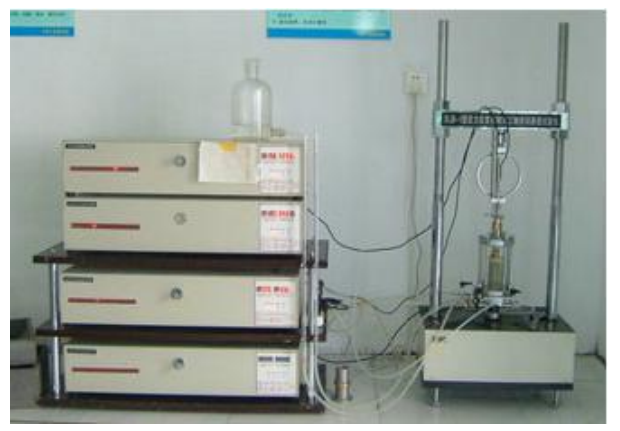

Fig. 3 SLB-1 stress-strain controlled triaxial shear penetration apparatus

Test Apparatus. This experiment adopted SLB stress-strain controlled triaxial shear penetration apparatus. The apparatus belongs to multifunctional flexible controlled triaxial apparatus, which could conduct many experiments such as the same stress-strain control of triaxial test, UU,CU,CD test, anisotropic or isotropic consolidation test, the saturation under counter pressure test, $K_{0}$ test and permeate test. The basic structure of apparatus is shown by Fig. 3 .

Sample Preparation. Because the disturbance of soil samples can easily affect soil physics parameters, the quality of soil samples will be the first relates to the success or failure of the whole test. Soil samples are mucky clay and silty clay within the depth of 20 meters, adopting the method of continuous pressure. The sample 'diameter is $39.1 \mathrm{~mm}$ and the height is $80 \mathrm{~mm}$. The process of 
discharge, transportation and storage should be taken strict monitor. The measured results of soil's physical indexes are shown by Table 2 .

Table 2. Basic physics of each soil layer

\begin{tabular}{ccccccc}
\hline $\begin{array}{c}\text { The type of } \\
\text { soil }\end{array}$ & $\begin{array}{c}\text { Water } \\
\text { content } \\
w[\%]\end{array}$ & $\begin{array}{c}\text { Nutural } \\
\text { density } \\
\gamma\left[\mathrm{KN} / \mathrm{m}^{3}\right]\end{array}$ & $\begin{array}{c}\text { Specific } \\
\text { gravity } \\
G s\end{array}$ & $\begin{array}{c}\text { Void ratio } \\
e_{0}\end{array}$ & $\begin{array}{c}\text { Liquidity } \\
\text { index } \\
I_{1}\end{array}$ & $\begin{array}{c}\text { Plasticity } \\
\text { index } \\
I_{\mathrm{p}}\end{array}$ \\
\hline Silty clay & 31 & 18.5 & 2.68 & 0.78 & 0.45 & 15.2 \\
mucky soil & 48 & 17.0 & 2.62 & 1.25 & 1.52 & 26.7 \\
\hline
\end{tabular}

Soil sample could be saturated by the saturated container. Put the sample into the saturated container and place it in the pump cylinder, when vacuum is close to 1 atmosphere, continue to extract air for 2 hours, and maintain vacuum stable, open the inlet valve, let water inject into cylinder. Close water valve after water soaking saturated, remove the vacuum and let it stay at least 10 hours, finalize sample preparation when saturation is more than $98 \%$.

\section{Conventional Triaxial Compression Test of Soil}

Conventional Triaxial Compression Test Program. Obtain samples of conventional triaxial compression test by drilling undisturbed soil from different depths. There are three samples for each type. The loading program is shown by Table 3 .

Table 3. Triaxial compression test scheme

\begin{tabular}{cccl}
\hline $\begin{array}{c}\text { The type of } \\
\text { soil }\end{array}$ & $\begin{array}{c}\text { The sample } \\
\text { number }\end{array}$ & $\begin{array}{c}\text { confining pressures } \\
{[\mathrm{KPa}]}\end{array}$ & Stress path \\
\hline \multirow{4}{*}{ Silty clay } & A-1 & 50 & Constant confining pressures, increscent axial pressure. \\
& A-2 & 100 & Constant confining pressures, increscent axial pressure. \\
& A-3 & 200 & Constant confining pressures, increscent axial pressure. \\
mucky soil & B-1 & 50 & Constant confining pressures, increscent axial pressure. \\
& B-2 & 100 & Constant confining pressures, increscent axial pressure. \\
& B-3 & 200 & Constant confining pressures, increscent axial pressure. \\
\hline
\end{tabular}

Stress-strain Curve. According to stress path in Table 3, measure stress-strain curves of two types of soil under the conventional triaxial compression, which are shown in Figs. 4 and 5. respectively.

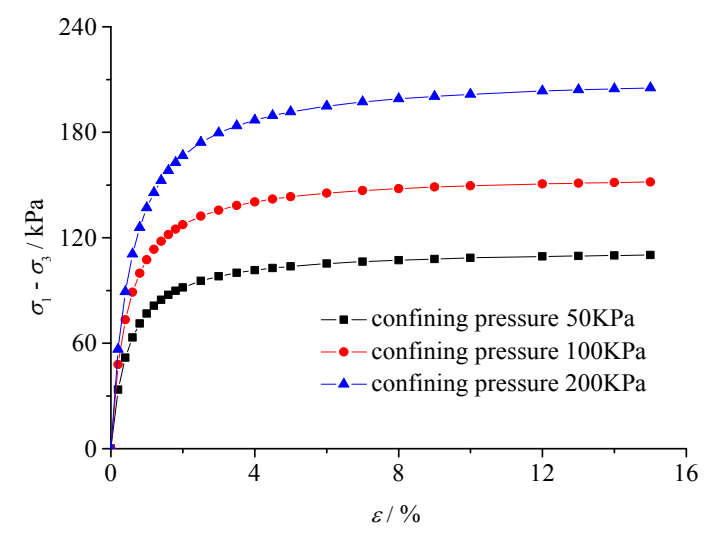

Fig. $4\left(\sigma_{1}-\sigma_{3}\right)-\varepsilon$ curves of silty clay under conventional triaxial test

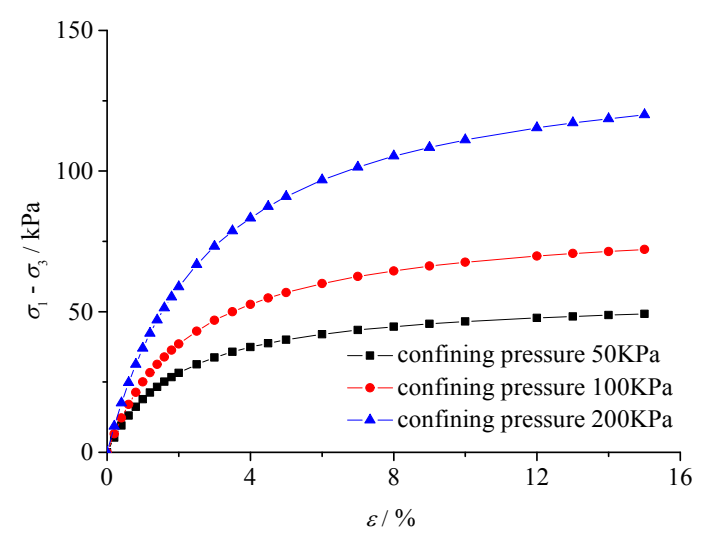

Fig. $5\left(\sigma_{1}-\sigma_{3}\right)-\varepsilon$ curves of mucky soil under conventional triaxial test 
Through comparing Fig. 4 with Fig. 5, stress-strain relation curves of two kinds of soil samples under conventional triaxial compression test have the following characteristics:

(1) The stress increases with the increase of strain in the initial stage of external loads, but when stress increases to a certain value, its increasing margin slows down rapidly while the strain increases rapidly. The relation curve presents work hardening.

(2) For the same type of soil samples, with the increase of consolidation pressure, the stress-strain curve steepens, the initial tangent modulus increases, the limiting stress increases.

(3) Comparing the stress-strain curves of two kinds of soils, we could know that under the same average consolidation pressure, to achieve the same strain, soil samples with small plastic index need more principal stress difference and the principal stress difference is bigger when soil fails.

\section{$K_{0}$ Consolidation Test of Soils}

$K_{0}$ Consolidation Triaxial Compression Test Program. When $K_{0}=1-\sin \varphi$ ', $\varphi^{\prime}$ is the effective internal frictional angle of soil measured by the way of conventional triaxial consolidation undrained test, the loading method is shown by Table 4. After the load at all levels is done, and ensuring the degree of consolidation is more than $95 \%$, then go on next level's loading.

Table 4. $K_{0}$ consolidated triaxial compression test scheme

\begin{tabular}{cccl}
\hline $\begin{array}{c}\text { The type of } \\
\text { soil }\end{array}$ & $\begin{array}{c}\text { The sample } \\
\text { number }\end{array}$ & $\begin{array}{c}\text { Confining pressures } \\
{[\mathrm{KPa}]}\end{array}$ & Stress path \\
\hline \multirow{4}{*}{ Silty clay } & A-4 & 50 & Constant confining pressures, increscent axial pressure \\
& A-5 & 100 & Constant confining pressures, increscent axial pressure \\
& A-6 & 200 & Constant confining pressures, increscent axial pressure \\
\multirow{5}{*}{ Mucky soil } & B-4 & 50 & Constant confining pressures, increscent axial pressure \\
& B-5 & 100 & Constant confining pressures, increscent axial pressure \\
& B-6 & 200 & Constant confining pressures, increscent axial pressure \\
\hline
\end{tabular}

Stress-strain Curve. According to stress path in Table 4. We could measure stress-strain curves of two kinds of soils shown by Fig. 6 and Fig. 7 under $K_{0}$ consolidation compression. Combined with the results of conventional triaxial test. We can draw conclusions below:

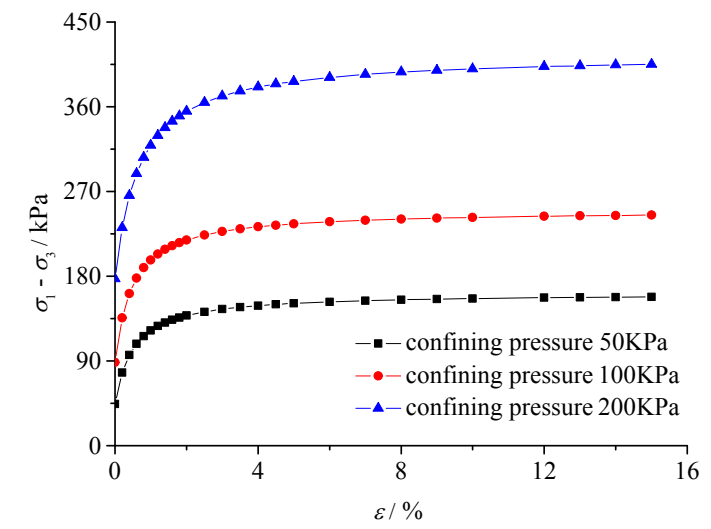

Fig. $6\left(\sigma_{1}-\sigma_{3}\right)-\varepsilon$ curves of silty clay under $K_{0}$ consolidation

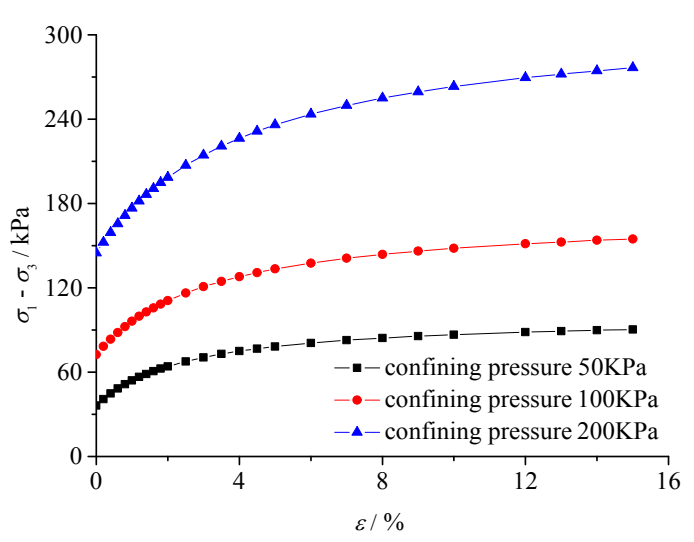

Fig. $7\left(\sigma_{1}-\sigma_{3}\right)-\varepsilon$ curves of mucky soil under $K_{0}$ consolidation

(1) Previous consolidation pressure has great influence on soil's strength index.

(2) The results measured by conventional triaxial compression test are a little less than the results measured by $K_{0}$ consolidation triaxial compression test. 
(3) Under the condition of $K_{0}$ consolidation, through comparing the stress-strain curves of two kinds of soils, we could know that under the same average consolidation pressure, to achieve the same strain, soil sample with small plastic index need more principal stress difference and the principal stress difference is bigger when soil fails.

\section{The Lateral Unloading Test of Soil}

The Lateral Unloading Test Program of Soil. Samples respectively unloaded confining pressures until the shear destruction after $K_{0}$ drained consolidation. The concrete test program is shown by Table 5.

Table 5. Lateral unloading stress path test under different confining pressures scheme

\begin{tabular}{cccc}
\hline $\begin{array}{c}\text { The type of } \\
\text { soil }\end{array}$ & $\begin{array}{c}\text { The sample } \\
\text { number }\end{array}$ & $\begin{array}{c}\text { confining pressures } \\
{[\mathrm{KPa}]}\end{array}$ & Stress path \\
\hline \multirow{3}{*}{ Silty clay } & A-7 & 50 & Constant axial pressure, horizontal unloading \\
& A-8 & 100 & Constant axial pressure, horizontal unloading \\
& A-9 & 200 & Constant axial pressure, horizontal unloading \\
mucky soil & B-7 & 50 & Constant axial pressure, horizontal unloading \\
& B-8 & 100 & Constant axial pressure, horizontal unloading \\
& B-9 & 200 & Constant axial pressure, horizontal unloading \\
\hline
\end{tabular}

Stress-strain Curves. According to stress path in Table 5, when lateral unloads after drained consolidation, the stress-strain curves of two types of soils are measured and shown by Fig. 8 and Fig. 9. By comparing Fig.8 with Fig.9, we can know the unloading mechanical properties of soil in lateral unloading area show the following rules:

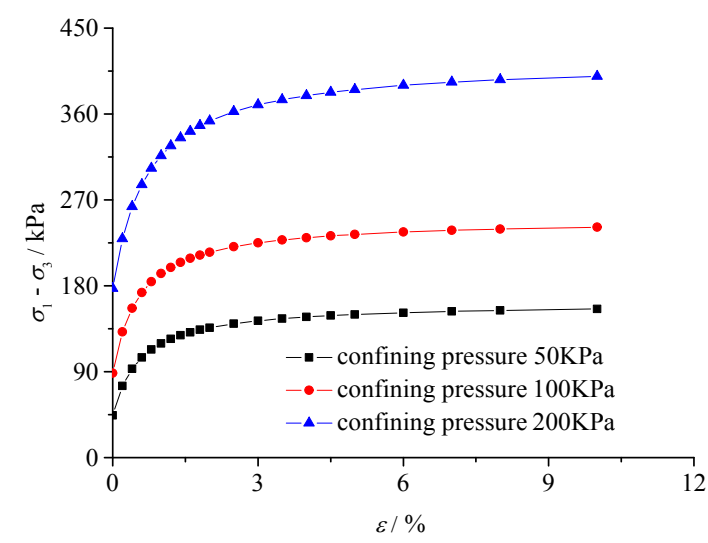

Fig. $8\left(\sigma_{1}-\sigma_{3}\right)-\varepsilon$ curves of silty clay under lateral unloading

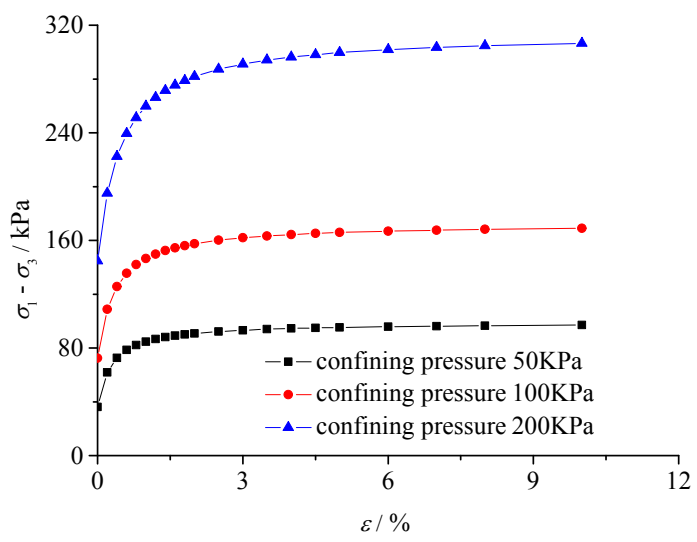

Fig. $9\left(\sigma_{1}-\sigma_{3}\right)-\varepsilon$ curves of mucky soil under lateral unloading

(1) The stress-strain curves show obvious nonlinear quality.

(2) For the same type of soil samples, peak value of the deviatoric stress increases with the increase of consolidation pressure.

(3) Comparing the stress-strain curves of two kinds of soils, we could know that under the same average consolidation pressure, to achieve the same strain, soil samples with small plastic index need more principal stress difference and the principal stress difference is bigger when soil fails.

\section{The Axial Unloading Test of Soil}

The Axial Unloading Test Program of Soil. The axial unloading test program of soil is shown by Table 6. 
Stress-strain Curve. According to stress path in Table 6, the stress-strain curves of two types of soils are measured and shown by Fig. 10 and Fig. 11 when axial unloads. By comparing Fig. 10 and Fig. 11, we can know the unloading mechanical properties of soil in axial unloading area show the following rules:

Table 6. Axial unloading stress path test under different confining pressures scheme

\begin{tabular}{cccl}
\hline $\begin{array}{c}\text { The type of } \\
\text { soil }\end{array}$ & $\begin{array}{c}\text { The sample } \\
\text { number }\end{array}$ & $\begin{array}{c}\text { confining pressures } \\
{[\mathrm{KPa}]}\end{array}$ & Stress path \\
\hline \multirow{4}{*}{ Silty clay } & A-7 & 50 & Constant confining pressures, axle unloading \\
& A-8 & 100 & Constant confining pressures, axle unloading \\
& A-9 & 200 & Constant confining pressures, axle unloading \\
mucky soil & B-7 & 50 & Constant confining pressures, axle unloading \\
& B-8 & 100 & Constant confining pressures, axle unloading \\
& B-9 & 200 & Constant confining pressures, axle unloading \\
\hline
\end{tabular}

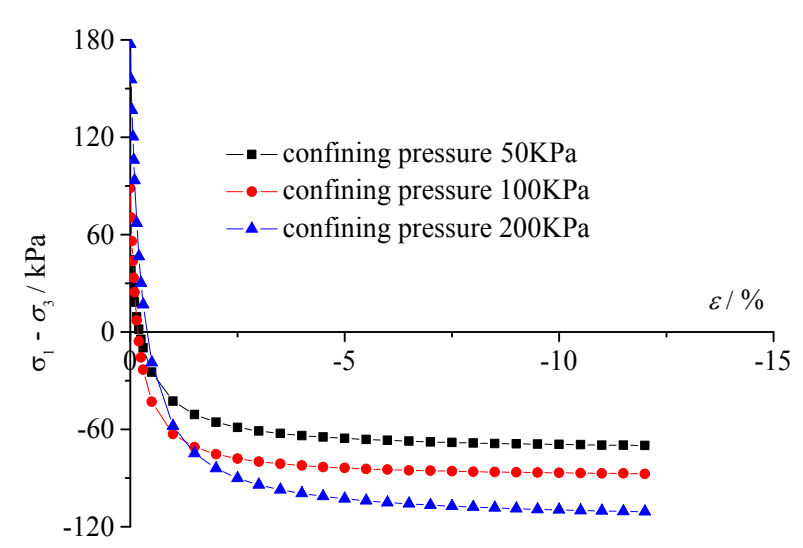

Fig. $10\left(\sigma_{1}-\sigma_{3}\right)-\varepsilon$ curves of silty clay under axial unloading

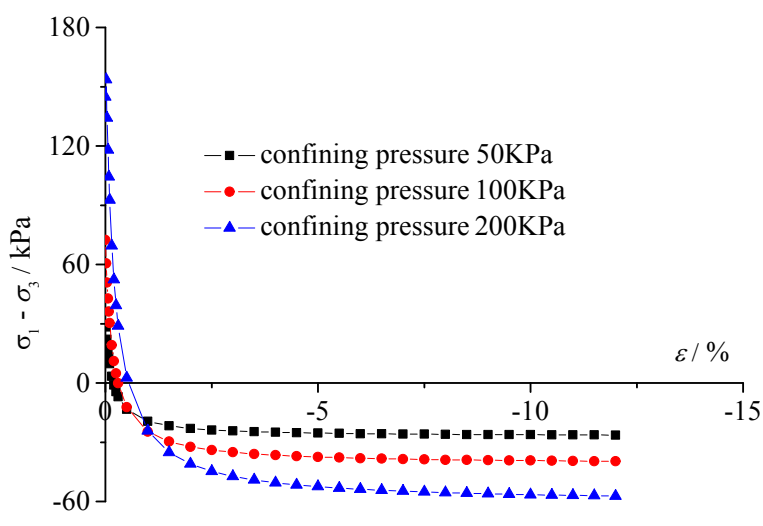

Fig. $11\left(\sigma_{1}-\sigma_{3}\right)-\varepsilon$ curves of mucky soil under axial unloading

(1) the stress-strain curves of soil samples show nonlinear quality. During the process of axial unloading, the failure model of soil doesn't present compression-shear type, but presents axial elongated type. The development law of axial unloading stress-strain curves is obviously different from axial loading stress-strain curves and lateral unloading stress-strain curves.

(2) Through comparing the stress-strain curves of two kinds of soils, we could know that under the same average consolidation pressure, to achieve the same strain, soil sample with small plastic index need more principal stress difference (absolute value) and the principal stress difference is bigger when soil fails.

The Contrastive Analysis Between $K_{0}$ Consolidation Loading Test and $K_{0}$ Consolidation Unloading Test. Mucky soil is used as research object and the stress-strain curves measured by $K_{0}$ consolidation loading and lateral unloading test are shown by Fig. 12, Fig. 13 and Fig. 14.

We could draw conclusions by the comparison of Fig. 12, Fig. 13 and Fig. 14:

(1) In triaxial loading test, the strain of soil increases along with the increase of the deviatoric stress, while the progress of elastic-plastic deformation appears before the axial strain reaches around $4 \%$ and then give priority to plastic deformation. The deviatoric stress hasn't changed much after the axial strain reaches around $6 \%$.

(2) Whether it is loading or unloading, confining pressures increase along with the increase of the failure principal stress. What is different is that the growth rate of the failure principal stress is relatively slow during unloading and that the change of the failure principal stress gradually slows down under the bigger confining pressures. But when loading, the growth rate of the failure principal stress is relatively rapid along with the increase of confining pressures. 
(3) In the experiment which soil shows compression shear failure, soil samples have good deformation and the failure of each sample occurred after exceeding the stain limit $(15 \%)$, the destruction condition of normal loading test of soil samples is determined by deformation. In the experiment which soil shows elongation destruction, the failure of each soil sample occurred before reaching strain limit (among 10\% 12\%).

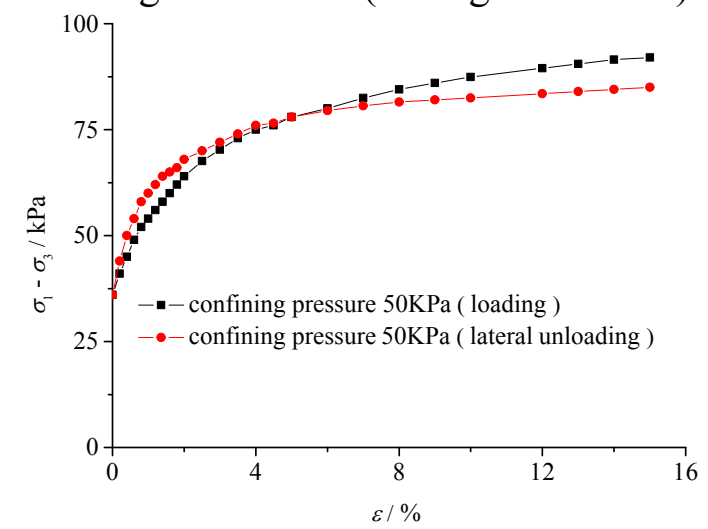

Fig. 12 Stress-strain curves under loading and unloading when the confining pressure is $50 \mathrm{kPa}$ under $K_{0}$ consolidation

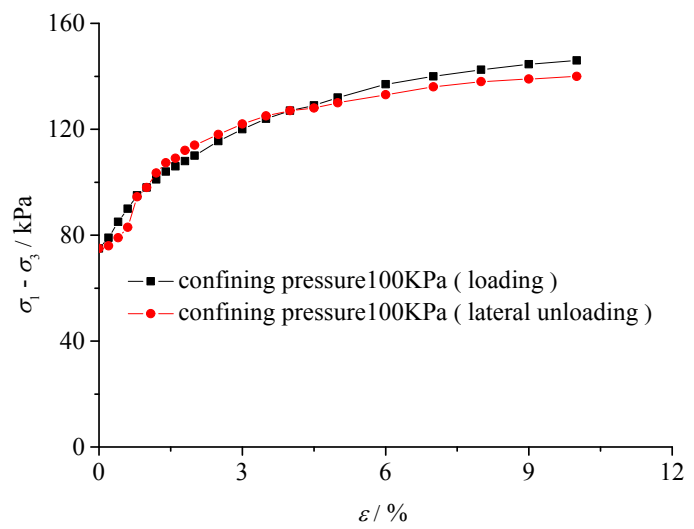

Fig. 13 Stress-strain curves under loading and unloading when the confining pressure is $100 \mathrm{kPa}$ under $K_{0}$ consolidation

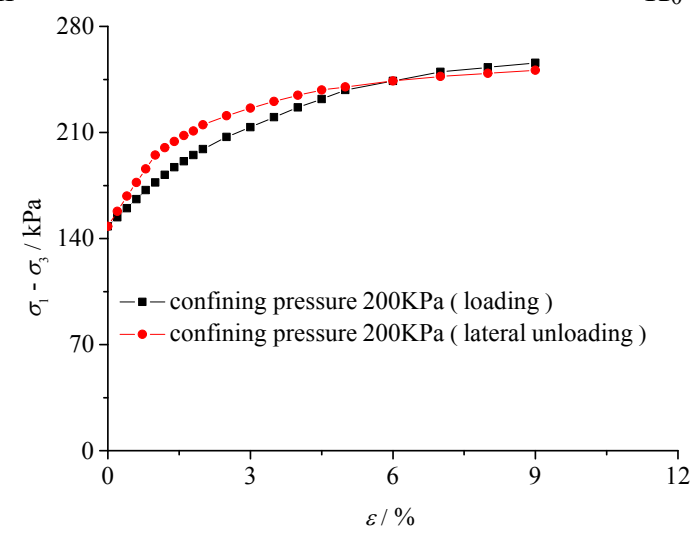

Fig. 14 Stress-strain curves under loading and unloading when the confining pressure is $200 \mathrm{kPa}$ under $K_{0}$ consolidation

\section{Law of Pore Water Pressure Under Different Stress Path}

According to the test results under different stress paths, the curves between pore water pressure and axial strain are mapped and shown from Fig. 15 to Fig. 22.

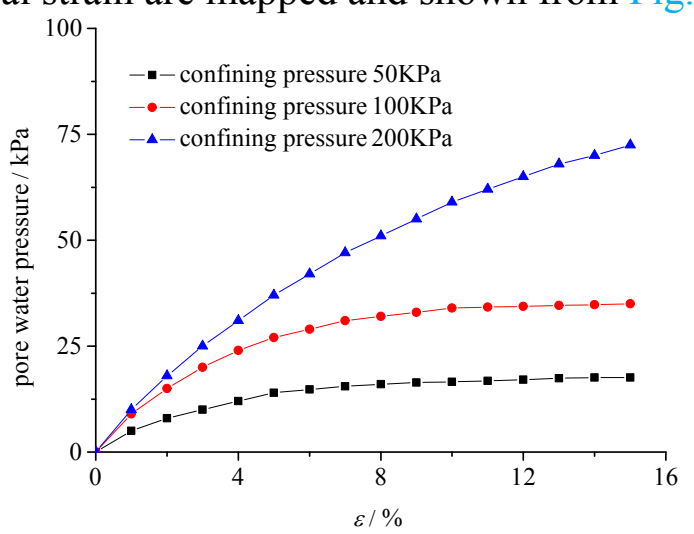

Fig. 15 Pore water pressure-strain curves of silty clay under conventional triaxial test

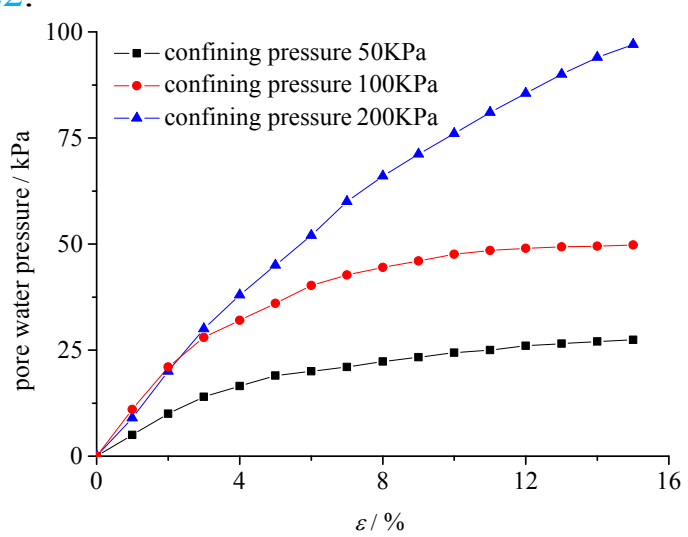

Fig. 16 Pore water pressure-strain curves of silty clay under $K_{0}$ consolidation loading 


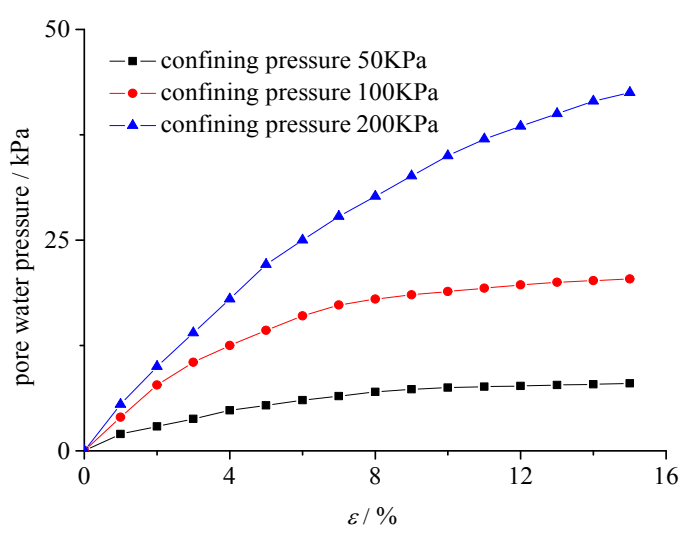

Fig. 17 Pore water pressure-strain curves of silty clay under $K_{0}$ consolidation lateral unloading

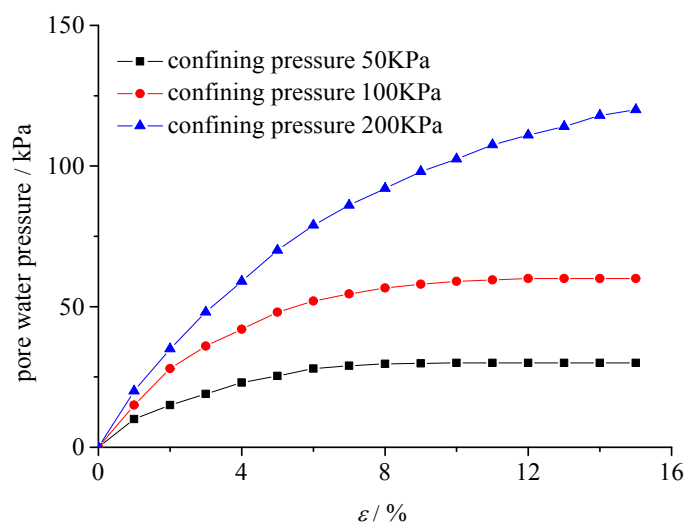

Fig. 19 Pore water pressure-strain curves of mucky soil under conventional triaxial test

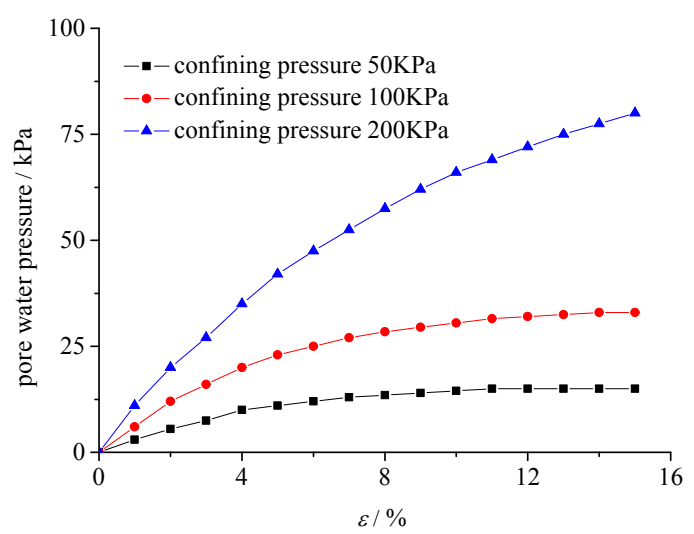

Fig. 21 Pore water pressure-strain curves of mucky soil under $K_{0}$ consolidation lateral unloading

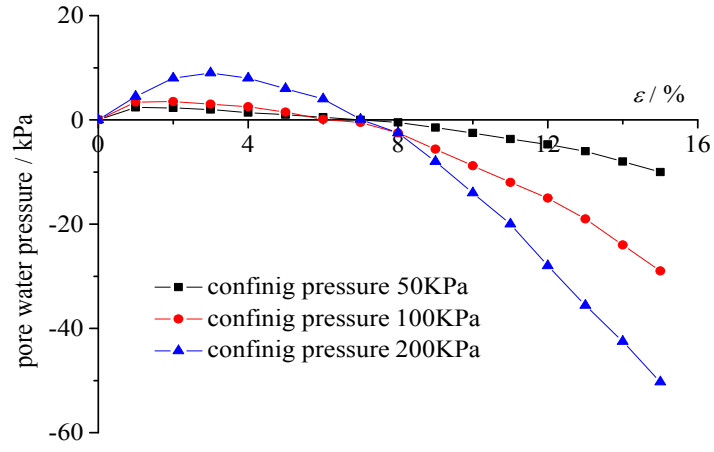

Fig. 18 Pore water pressure-strain curves of silty clay under $K_{0}$ consolidation axial unloading

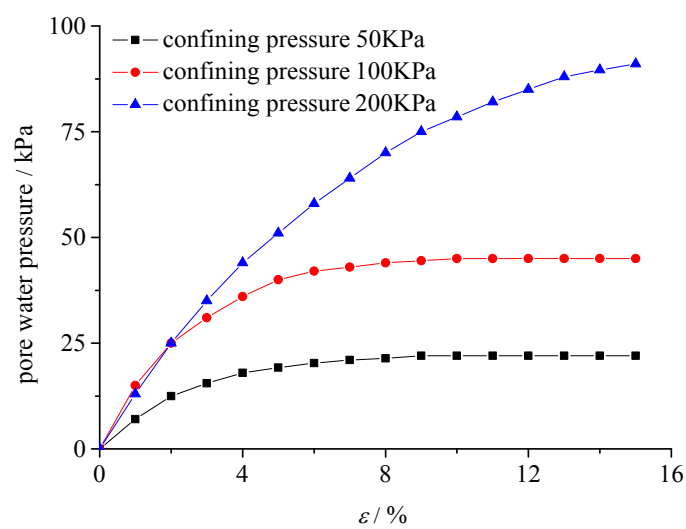

Fig. 20 Pore water pressure-strain curves of mucky soil under $K_{0}$ consolidation loading

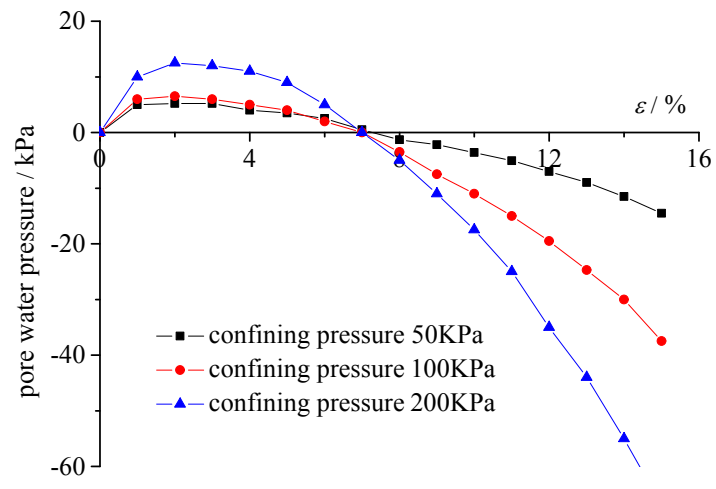

Fig. 22 Pore water pressure-strain curves of mucky soil under $K_{0}$ consolidation axial unloadin

We could draw the conclusion from Fig. 15 to Fig. 22 that the law of pore water pressure is related to average consolidation pressure, stress path, quality of soil ect.

(1) For the same kind of soil, the greater the average consolidation pressure, the bigger the pore water pressure.

(2) The pore water pressure which is under conventional triaxial test, $K_{0}$ consolidation triaxial loading test, $K_{0}$ consolidation triaxial lateral unloading test has similar law along with strain change. The pore water pressure increases rapidly in the early time and then the growth rate gradually becomes gently. For the same kind of soil and same average consolidation pressure, the increase of conventional triaxial test is the fastest, followed by $K_{0}$ consolidation triaxial loading test and $K_{0}$ consolidation triaxial lateral unloading test.

(3) The law of pore water pressure in $K_{0}$ consolidation triaxial axial unloading test along with the strain is different from the above three tests results. There is negative pore water pressure value 
during the back phase of the test, which illustrates that the volume of soil has the trend of expanding after experiencing axial unloading stress path in which the dilatancy behaviour of soil performs obviously.

(4) By comparing the law of pore water pressure of we could see that at the same stress path and average consolidation pressure, the smaller plastic index is, the faster the pore water pressure increases.

(5) By the result of test, pore water pressure-strain curves under different stress paths can be fit and the results are shown from Table 7 to Table10. The pore water pressure-strain curves at conventional triaxial test, $K_{0}$ consolidation triaxial loading test, $K_{0}$ consolation triaxial lateral unloading test can be fitted by exponential decay function (1).

$$
y=A_{1} \cdot \operatorname{EXP}\left(-x / T_{1}\right)+y_{0}
$$

The curves of the pore water pressure changing with the strain at $K_{0}$ consolidation triaxial axial unloading test can be divided into two parts, the early part and the latter part, which can be fit by quadratic parabola (2).

$$
y=a x^{2}+b x+c
$$

Table 7 Fitting coefficient of pore water pressure-strain curves under conventional triaxial test

\begin{tabular}{cccccc}
\hline $\begin{array}{c}\text { The type of } \\
\text { soil }\end{array}$ & $\begin{array}{c}\text { Consolidation } \\
\text { pressure }[\mathrm{KPa}]\end{array}$ & $y_{0}$ & $A_{1}$ & $T_{1}$ & $R^{2}$ \\
\hline \multirow{3}{*}{ Silty clay } & 50 & 26.93 & -26.93 & 4.72 & 0.85 \\
& 100 & 147.49 & -147.49 & 13.73 & 0.97 \\
& 200 & 48.95 & -48.95 & 3.80 & 0.79 \\
\multirow{3}{*}{ Mucky soil } & 50 & 29.12 & -29.12 & 2.76 & 0.69 \\
& 100 & 59.50 & -59.50 & 3.14 & 0.73 \\
& 200 & 134.02 & -134.02 & 7.06 & 0.92 \\
\hline
\end{tabular}

Table 8 Fitting coefficient of pore water pressure-strain curves under $K_{0}$ consolidation loading

\begin{tabular}{cccccc}
\hline $\begin{array}{c}\text { The type of } \\
\text { soil }\end{array}$ & $\begin{array}{c}\text { Consolidation } \\
\text { pressure }[\mathrm{KPa}]\end{array}$ & $y_{0}$ & $A_{1}$ & $T_{1}$ & $R^{2}$ \\
\hline \multirow{3}{*}{ Silty clay } & 50 & 16.45 & -16.45 & 3.61 & 0.77 \\
& 100 & 34.25 & -34.25 & 3.63 & 0.78 \\
& 200 & 92.24 & -92.24 & 10.48 & 0.96 \\
\multirow{3}{*}{ Mucky soil } & 50 & 21.75 & -21.75 & 2.49 & 0.65 \\
& 100 & 44.79 & -44.79 & 2.44 & 0.64 \\
& 200 & 104.79 & -104.79 & 7.49 & 0.93 \\
\hline
\end{tabular}

Table 9 Fitting coefficient of pore water pressure-strain curves under $K_{0}$ consolidation lateral unloading

\begin{tabular}{cccccc}
\hline $\begin{array}{c}\text { The type of } \\
\text { soil }\end{array}$ & $\begin{array}{c}\text { Consolidation } \\
\text { pressure }[\mathrm{KPa}]\end{array}$ & $y_{0}$ & $A_{1}$ & $T_{1}$ & $R^{2}$ \\
\hline \multirow{3}{*}{ Silty clay } & 50 & 8.64 & -8.64 & 5.78 & 0.89 \\
& 100 & 20.58 & -20.58 & 4.20 & 0.82 \\
& 200 & 54.97 & -54.97 & 10.39 & 0.96 \\
Mucky soil & 50 & 15.59 & -15.59 & 5.03 & 0.86 \\
& 100 & 34.25 & -34.25 & 4.85 & 0.85 \\
& 200 & 99.28 & -99.28 & 9.38 & 0.95 \\
\hline
\end{tabular}


Table 10 Fitting coefficient of pore water pressure-strain curves under $K_{0}$ consolidation axial unloading

\begin{tabular}{cccccccccc}
\hline $\begin{array}{c}\text { The type of } \\
\text { soil }\end{array}$ & $\begin{array}{c}\text { Consolidation } \\
\text { pressure [KPa] }\end{array}$ & $\begin{array}{c}\text { Early stage } \\
a_{1}\end{array}$ & $b_{1}$ & $c_{1}$ & $R^{2}{ }_{1}$ & $a_{2}$ & $b_{2}$ & $c_{2}$ & $R^{2}{ }_{2}$ \\
\hline \multirow{3}{*}{ Silty clay } & 50 & -0.26 & 2.76 & 0 & 1.00 & -0.06 & 0.12 & 2.43 & 0.94 \\
& 100 & -0.34 & 2.94 & 0 & 0.99 & -0.19 & 0.76 & 3.74 & 0.94 \\
& 200 & -0.66 & 5.66 & 0 & 0.99 & -0.42 & 2.10 & 7.36 & 0.92 \\
Mucky soil & 50 & -4.00 & 8.00 & 0 & 1.00 & -0.09 & 0.20 & 4.10 & 0.94 \\
& 100 & -3.11 & 9.33 & 0 & 0.94 & -0.24 & 0.73 & 6.44 & 0.95 \\
& 200 & -3.00 & 12.00 & 0 & 0.92 & -0.47 & 1.88 & 10.12 & 0.94 \\
\hline
\end{tabular}

\section{The Shear Strength of Soil Under Different Stress Path}

On the coordinate system of normal stress-shear stress, let $\left(\sigma_{1 f}+\sigma_{3 f}\right) / 2$ be as center and $\left(\sigma_{1 f}-\sigma_{3 f}\right) / 2$ be as radius, to draw ultimate Mohr circle to calculate the total stress strength parameters. Now soil Mohr circle of two types under different stress paths and strength envelope are shown from Fig. 23 to Fig. 28.

From the strength envelope diagram of each soil sample, we can draw the conclusion that the results of normal loading test are different from unloading triaxial test. The compare of the mechanical parameters of soil between conventional triaxial compression test and lateral unloading test is shown by Table. 11.

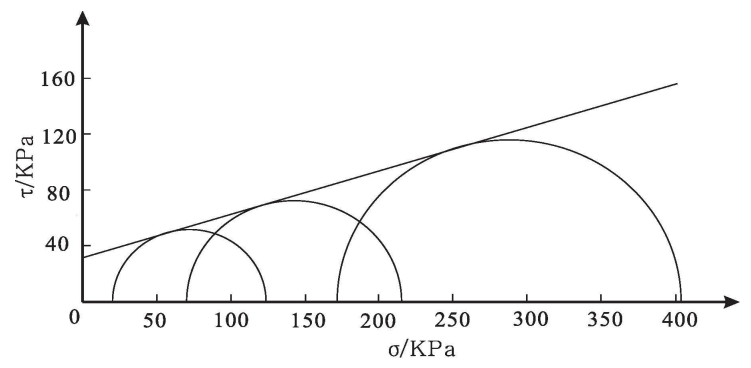

Fig. 23 Strength envelope of silty clay under conventional triaxial test

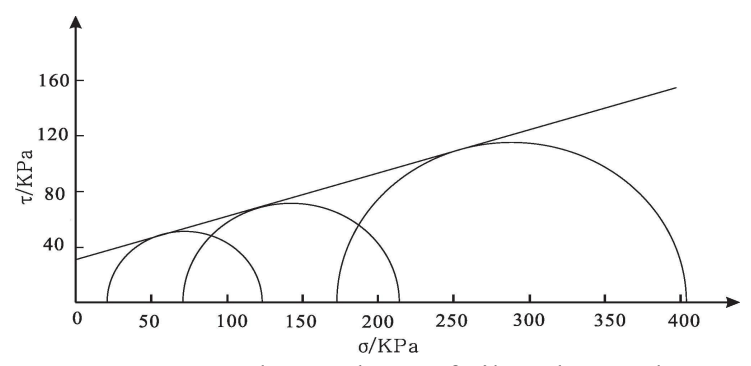

Fig. 25 Strength envelope of silty clay under $K_{0}$ consolidation lateral unloading

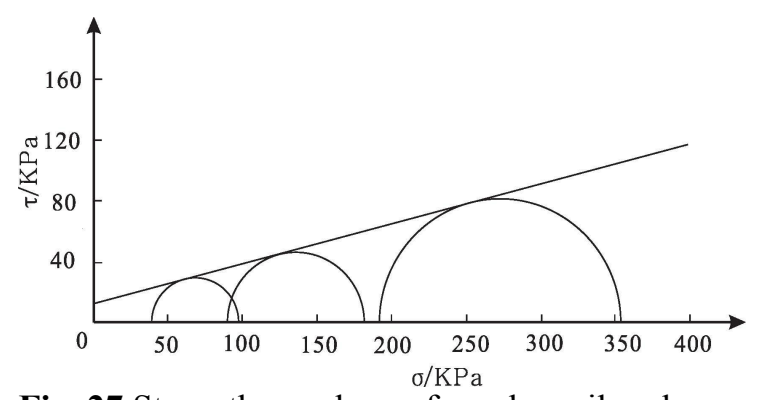

Fig. 27 Strength envelope of mucky soil under $K_{0}$ consolidation loading

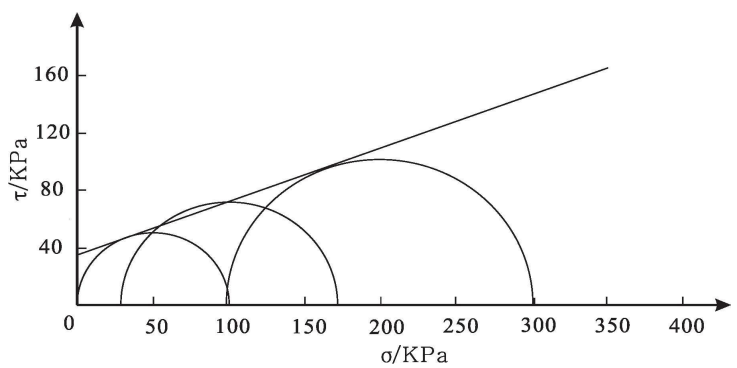

Fig. 24 Strength envelope of silty clay under $K_{0}$ consolidation loading

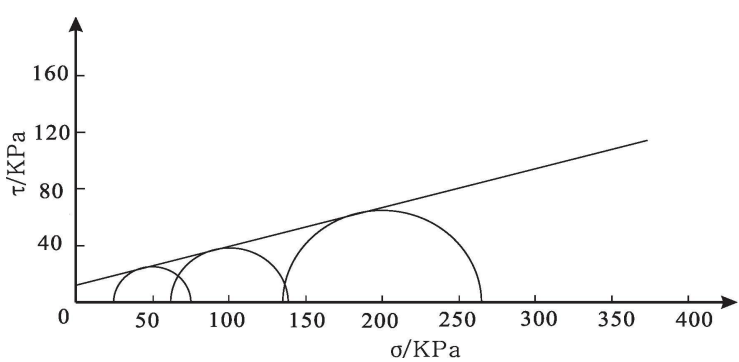

Fig. 26 Strength envelope of mucky soil under conventional triaxial test

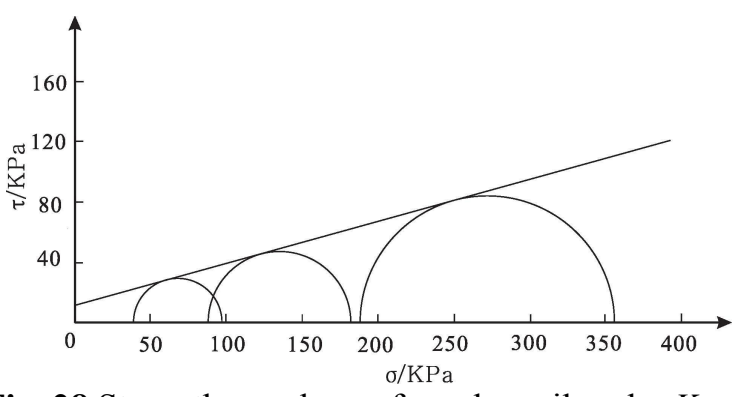

Fig. 28 Strength envelope of mucky soil under $K_{0}$ consolidation lateral unloading 
Table 11 Comparison of soil mechanics parameters under conventional triaxial compression and lateral unloading test

\begin{tabular}{cccc}
\hline Soil mechanics parameters & Loading method & Silty clay & mucky soil \\
\hline \multirow{2}{*}{ Internal friction angle [ $\left.{ }^{\circ}\right]$} & Normal loading & 14.0 & 18.0 \\
& Lateral unloading condition & 13.2 & 16.5 \\
\multirow{2}{*}{ Cohesive force $[\mathrm{KPa}]$} & Normal loading & 9.0 & 21.5 \\
& Unloading condition & 10.5 & 22.0 \\
\hline
\end{tabular}

\section{Conclusions}

(1) The stress-strain curves of soil under different stress paths show obvious nonlinear quality, while $K_{0}$ consolidation triaxial compression test and lateral unloading test show the quality of axial compression. The unloading deformation curves of soil in axial unloading test have different characteristics compared with previous two tests and axial unloading test shows axial elongation quality.

(2) Axial load didn't change during lateral unloading test. When each sample is under small consolidation pressure, the ultimate strain increases with the increase of consolidation pressure, but after reaching a certain stress level, the strain was not increased. So, when lateral unloading, the soil of smaller consolidation stress can reach the shear strength and fails at small strain condition.

(3) Whether it is loading or unloading, confining pressures increase along with the increase of the failure principal stress. What is different is that the growth rate of the failure principal stress is relatively slow during unloading and that the change of the failure principal stress gradually slows down under the bigger confining pressures. But when loading, the growth rate of the failure principal stress is relatively rapid along with the increase of confining pressures.

(4) In the experiment which soil shows compression shear failure, soil samples have good deformation and the failure of each sample occurred after exceeding the stain limit $(15 \%)$, the destruction condition of conventional loading test of soil samples is determined by deformation. In the experiment which soil shows elongation destruction, the failure of each soil sample occurred before reaching strain limit(among 10\% 12\%).

(5) The shear strength index of soil under lateral unloading is similar to that under normal loading. In the process of practical engineering calculation, the shear strength index under normal loading can replace the shear strength index under lateral unloading.

(6) Under the same average consolidation pressure, to achieve the same strain, soil samples with small plastic index need more principal stress difference, and the principal stress difference is bigger when soil fails.

(7) For the same soil, the more average consolidation stress, the more pore water pressure. The pore water pressure which is under conventional triaxial test, $K_{0}$ consolidation triaxial loading test, $K_{0}$ consolidation triaxial lateral unloading test has similar law along with strain change. The pore water pressure increases rapidly in the early time and then the growth rate gradually becomes gentle. For the same kind of soil and same average consolidation pressure, the increase of conventional triaxial test is the fastest, followed by $K_{0}$ consolidation triaxial loading test and $K_{0}$ consolidation triaxial lateral unloading test .

(8)The law of pore water pressure in $K_{0}$ consolidation triaxial axial unloading test along with the strain is different from the above three tests results. There is negative pore water pressure value during the back phase of the test, which illustrates that the volume of soil has the trend of expanding after experiencing axial unloading stress path in which the dilatancy behaviour of soil performs obviously.

(9)At the same stress path and average consolidation pressure, the smaller plastic index is, the faster pore water pressure growth.

(10)The pore water pressure-strain curves at conventional triaxial test, $K_{0}$ consolidation triaxial loading test, $K_{0}$ consolation triaxial lateral unloading test can be fitted by exponential decay function (1). The curves of the pore water pressure changing with the strain at $K_{0}$ consolidation triaxial axial 
unloading test can be divided into two parts, the early part and the latter part, which can be fit by quadratic parabola (2).

\section{Acknowledgements}

This work was supported by the National Natural Science Foundation of China (51308065), Natural Science Foundation of Shaanxi Province (2016JM5050) and the Fundamental Research Funds for the Central University (310828173401).

\section{References}

[1] T.W. Lambe: J. Soil. Mech. Found. Div. Vol. 93 (1967), p. 309-331

[2] HE Shi-xiu, HAN Gao-sheng: Rock. Soil. Mech. Vol. 24 (2003), p. 17-20

[3] CHEN Guo-qing, WANG Yan-shen, et al: Chin. J. Rock. Mech. Eng. Vol. 33 (2014), p. 2996-3002.

[4] MEI Guo-xiong, CHEN Hao, et al: Chin. J. Rock. Mech. Vol. 29 (2010), p. 3108-3112.

[5] HUANG Hao-ran, ZHU Jun-gao, et al: J. Disaster. Prevent. Mitig. Eng. Vol. 35 (2012), p. 546-551.

[6] CHEN Lin-jing, DAI Zi-hang, et al: Rock. Soil. Mech.Vol. 32 ( 2011), p. 3249-3257.

[7] CHU Fu-yong, ZHU Jun-gao, et al: Rock. Soil. Mech. Vol. 33 (2012), p. 1625-1630.

[8] SHI Jian-yong, LEI Guo-hui, et al: Rock. Soil. Mech. Vol. 26 (2005), p. 1700-1704.

[9] YING Hong-wei, NIE Wen-feng, et al: Rock. Soil. Mech. Vol. 32(2011), p. 129-133.

[10]Zhou Yuanzhong, LiuXinrong, et al: J. Chongqing. Univ. Vol. 37 (2014), p. 17-24.

[11]Qin Peng-fei, Xie Xiao-jie, et al: J. Yangtze. River. Sci. Res. Inst. Vol. 33 (2016), p. 78-80,85.

[12]Liu Pan, Zhou Xiao-wen, et al: J. Yangtze. River. Sci. Res. Inst. Vol. 33 (2016), p. 70-74.

[13]Huang Yong, Liu Gan-bin, et al: Hydrogeol Eng Geol. Vol. 43 (2016), p. 83-87.

[14]Abdulhadi NO, Germaine JT, et al: Can. Geotech. J. Vol. 49 (2012), 907-916.

[15]ZHAO Xin, CHEN Xue-jun, et al: Sichuan. Build. Sci. Vol. 36 (2010), p. 117-119.

[16]ZHAO Xin, CHEN Xue-jun, et al: Sichuan. Build. Sci. Vol. 36 (2010), p. 97-99.

[17]MA Xiao-wen, AI Ying-bo: Chin. J. Geotech. Eng. Vol. 33 (2011), 182-186. 